\title{
Sickle cell retinopathy in Jamaican children: a search for prognostic factors
}

\author{
J. F. TAlBOT, A. C. BIRD, L. M. RABB, G. H. MAUdE, and G. R. SERJEANT \\ From the Medical Research Council Laboratories (Jamaica), University of the West Indies, Kingston, Jamaica
}

SUMMARY Children with homozygous sickle cell (SS) disease and with sickle cell-haemoglobin C (SC) disease, aged $6 \frac{1}{2}$ to $8 \frac{1}{2}$ years, were examined by fluorescein angiography/angioscopy to determine the presence of retinal nonperfusion. The haematological and clinical features of children with and without nonperfusion were compared. Retinal vessel closure was significantly correlated with low total haemoglobin, and high fetal haemoglobin, reticulocyte, and irreversibly sickled cell counts in SS disease, and with high reticulocyte count in SC disease. No relationships were apparent between vessel closure and other haematological indices or clinical events in either genotype.

Proliferative sickle retinopathy (PSR) is well recognised among adults with sickle cell disease, especially those with sickle cell-haemoglobin C (SC) disease, but the factors determining its development are only poorly understood. Recent haematological analyses in patients with and without PSR have indicated PSR to be significantly associated with high total haemoglobin and low fetal haemoglobin in homozygous sickle cell (SS) disease ${ }^{1}$ and with low fetal haemoglobin in SC disease. ${ }^{2}$ Age was also relevant, both genotypes showing a striking increase in the prevalence of PSR during adolescence. These analyses were relatively insensitive because the patients with PSR represented a heterogeneous group, having developed PSR at probably widely differing ages, and the age of development of PSR was often unknown. More accurate definition of the age of onset of retinal changes might be expected to allow detection of haematological and clinical factors relevant to the development of these changes. With this in mind prospective ocular assessments of a large representative sample of children with SS and SC disease is currently in progress.

The first report on ocular changes in this group ${ }^{3}$ showed that peripheral retinal nonperfusion occurred in both genotypes before the age of 7 years and was more frequently seen in SS disease. The current report extends these findings by further observations one year later and searches for haematological indices and clinical events of prognostic value.

Correspondence to Professor Graham R. Serjeant, Medical Research Council Laboratories, University of the West Indies, Mona, Kingston 7, Jamaica, West Indies.

\section{Material and methods}

The patient group and the methods of haematological diagnosis and of ophthalmological examination have been previously described. ${ }^{3}$ At the time of the present investigations (January 1982) children with SS and SC disease in the cohort study were aged up to $8^{1 / 2}$ years. Those aged over 5 years were asked to attend for detailed ophthalmoscopic examination.

Fluorescein angiography or angioscopy was performed on all children aged over $6 \frac{1}{2}$ years, and in those children with identifiable retinal abnormalities regardless of age, after informed consent had been given by the parents or guardians. This report is based only on those with fluorescein observations.

Of the children with SS disease angiography/ angioscopy failed or was not attempted in 4 due to lack of co-operation, and satisfactory studies were available in 54 children. Of the children with SC disease 10 failed to co-operate, and satisfactory studies were available in 31 children.

Fluorescein findings were classified according to evidence of retinal nonperfusion. Of the 54 patients with SS disease 18 showed no evidence of closure (group I), 18 had closure affecting up to $180^{\circ}$ of the circumference cumulative in both eyes (group II), and 18 had greater than $180^{\circ}$ involvement (group III). Patients with SC disease were divided into those with no evidence of closure (group I) and those with closure (group. II). Haematological analyses employed indices measured at age 6 years as described elsewhere. ${ }^{4}$ Irreversibly sickled cells (ISCs) were counted as previously described. ${ }^{5}$ Fetal haemo- 
Table 1 Age and sex distribution

\begin{tabular}{|c|c|c|c|c|c|c|}
\hline & \multirow[t]{2}{*}{ Group } & \multicolumn{3}{|c|}{$\begin{array}{l}\text { No. of } \\
\text { patients }\end{array}$} & \multicolumn{2}{|c|}{$\begin{array}{l}\text { Age at exam- } \\
\text { ination (mo.) }\end{array}$} \\
\hline & & Males & Females & Totals & Mean & $S D$ \\
\hline \multicolumn{7}{|l|}{ SS Disease } \\
\hline & I & 4 & 14 & 18 & 89 & $6 \cdot 2$ \\
\hline & II & 12 & 6 & 18 & 86 & $10 \cdot 8$ \\
\hline & III & 10 & 8 & 18 & 88 & $8 \cdot 8$ \\
\hline \multicolumn{7}{|l|}{$S C$ Disease } \\
\hline & I & 9 & 6 & 15 & 87 & $8 \cdot 0$ \\
\hline & II & 9 & 7 & 16 & 89 & $6 \cdot 6$ \\
\hline
\end{tabular}

globin (HbF), reticulocytes, and ISC's showed skewed distributions, and logarithmic transformation was performed prior to statistical analysis.

Clinical events in the groups were compared by examining the proportion of children experiencing dactylitis, acute chest syndrome (pneumonia or pulmonary infarction), painful crises, large bone infarctions, acute splenic sequestration, gastroenteritis, illnesses associated with weight loss equal to or more than $5 \%$ body weight, and illnesses with pyrexia equal to or higher than $102^{\circ} \mathrm{F}\left(38.9^{\circ} \mathrm{C}\right)$. Growth was used as anmedditional indicator of clinical severity. Height $(\mathrm{cm})$ was measured on a standing stadiometer (Holtain Instruments) and weight (kg) on a lever balance scale. Values were taken at age 6 years and interpolated from the growth curve for this age when necessary.

\section{Results}

SS DISEASE

Age and sex distribution. Details of age and sex in the 3 groups of retinal closure are shown in Table 1. The age distribution of patients with different degrees of closure was closely similar, indicating that closure did not simply reflect older age. Closure was
Table 3 Comparison of clinical events in SS patients according to degree of peripheral retinal closure (figures represent number of children affected)

\begin{tabular}{lcllll}
\hline Event & $I$ & $I I$ & $I I I$ & $\chi^{\Sigma}$ & Sig. $^{*}$ \\
\hline Dactylitis & 8 & 8 & 11 & $0 \cdot 08$ & NS \\
Pneumonia & $14(1 \cdot 9)$ & $16(2 \cdot 7)$ & $12(1 \cdot 8)$ & $1 \cdot 65$ & NS \\
Crisis and infarction & $15(4 \cdot 4)$ & $13(3 \cdot 6)$ & $14(3 \cdot 1)$ & $0 \cdot 12$ & NS \\
Acute splenic & & & & & \\
$\quad$ sequestration & 4 & 5 & 8 & $1 \cdot 82$ & NS \\
Gastroenteritis & 12 & 12 & 13 & $0 \cdot 00$ & NS \\
Weight loss $\geqslant 5 \%$ & 8 & 10 & 9 & $0 \cdot 03$ & NS \\
Temperature $\geqslant 102^{\circ} \mathrm{F}$ & 10 & 14 & 14 & $0 \cdot 45$ & NS \\
\hline
\end{tabular}

${ }^{*}$ Mantel-Haenzsel $\chi^{2}$ test for trend, allowing for age group. NS $=$ not significant $(p>0.05)$. A $\chi^{2}$ value of 3.84 would be required for significance of the $5 \%$ level.

Figures in parentheses represent mean number of events per child.

significantly more common in boys $\left(\chi^{2}=7 \cdot 7 ; \mathrm{p}<0.05\right)$.

Haematological indices. Means and standard deviations of indices for patients in the $\mathbf{3}$ groups are summarised in Table 2. Testing for trends with increasing degree of circumferential closure by analysis of variance indicated closure to be significantly associated with lower mean total haemoglobin and with higher reticulocyte counts $(p<0.05)$. Mean $\mathrm{HbF}$ levels were significantly lower $(\mathrm{p}<0.05)$ and ISC counts significantly higher $(p<0.01)$ in those with closure than those without but did not differ between the groups with different severities of closure.

These analyses did not allow for correlations between haematological indices or sex-related effects. Multiple logistic regression analysis ${ }^{6}$ was therefore used to examine whether occlusion was influenced jointly by a combination of variables. These analyses confirmed the association of occlusion (groups II and III combined) with lower HbF levels and with higher reticulocyte and ISC counts. ISC counts substituted well for $\mathrm{HbF}$ levels in the model, which was not surprising since both indices are strongly correlated, and ISC counts gave a marginally

Table 2 Comparison of haematological indices in SS patients according to degree of peripheral retinal closure

\begin{tabular}{|c|c|c|c|c|c|c|c|}
\hline \multirow[t]{2}{*}{ Index } & \multicolumn{2}{|l|}{ Group I } & \multicolumn{2}{|l|}{ Group II } & \multicolumn{2}{|l|}{ Group III } & \multirow[t]{2}{*}{ Significance $^{*}$} \\
\hline & Mean & $S D$ & Mean & $S D$ & Mean & $S D$ & \\
\hline $\mathrm{Hb}(\mathrm{g} / \mathrm{dl})$ & $7 \cdot 97$ & 1.06 & $7 \cdot 49$ & $1 \cdot 21$ & $7 \cdot 21$ & 0.99 & $\mathrm{p}<0.05$ \\
\hline $\log _{e}(\% \mathrm{HbF}+1)$ & $2 \cdot 22(8 \cdot 2)$ & $0 \cdot 37$ & $1 \cdot 65(4 \cdot 2)$ & 0.44 & $1 \cdot 83(5 \cdot 2)$ & 0.43 & $\mathrm{p}<0.05$ \\
\hline $\mathrm{MCHC}(\mathrm{g} / \mathrm{dl})$ & 33.5 & 1.92 & $34 \cdot 2$ & $2 \cdot 30$ & $34 \cdot 8$ & $2 \cdot 01$ & NS \\
\hline $\operatorname{RBC}\left(\times 10^{12} / 1\right)$ & $2 \cdot 86$ & 0.47 & 2.69 & 0.48 & $2 \cdot 60$ & 0.54 & NS \\
\hline $\operatorname{MCV}(f)$ & $83 \cdot 2$ & $9 \cdot 7$ & $81 \cdot 8$ & $8 \cdot 6$ & $85 \cdot 0$ & $8 \cdot 8$ & NS \\
\hline $\log _{e}(\%$ ISC+10) & $2 \cdot 57(3 \cdot 1)$ & $0 \cdot 15$ & $2 \cdot 83(7 \cdot 0)$ & $0 \cdot 34$ & $2 \cdot 78(6 \cdot 2)$ & 0.26 & $\mathrm{p}<0.05$ \\
\hline $\log _{e}(\%$ retics +1$)$ & $2 \cdot 38(9 \cdot 8)$ & 0.41 & $2 \cdot 62(12 \cdot 7)$ & 0.42 & $2.69(13 \cdot 7)$ & 0.39 & $\mathrm{p}<0.05$ \\
\hline Platelets $\left(x^{9} / 1\right)$ & 427 & 186 & 395 & 132 & 412 & 154 & NS \\
\hline Serum Fe $(\mu \mathrm{g} / \mathrm{dl})$ & $81 \cdot 1$ & 38.9 & $91 \cdot 8$ & $34 \cdot 2$ & $82 \cdot 5$ & $41 \cdot 6$ & NS \\
\hline
\end{tabular}

$\mathrm{NS}=$ not significant $(\mathrm{p}>0 \cdot 05)$.

Figures in parentheses represent means re-expressed in original units.

*Test for trend using analysis of variance. 
Table 4 Comparison of haematological indices in SC patients with and without peripheral retinal closure

\begin{tabular}{|c|c|c|c|c|c|c|}
\hline & \multicolumn{2}{|l|}{$I$} & \multicolumn{2}{|l|}{ II } & \multirow[b]{2}{*}{$t$} & \multirow[t]{2}{*}{ Significance } \\
\hline & Mean & $S D$ & Mean & $S D$ & & \\
\hline $\mathrm{Hb}(\mathrm{g} / \mathrm{dl})$ & $10 \cdot 96$ & 0.63 & $11 \cdot 00$ & 0.72 & $0 \cdot 16$ & NS \\
\hline $\log (\% \mathrm{HbF}+1)$ & $1.07(1.9)$ & 0.47 & $0.98(1.7)$ & $0 \cdot 50$ & 0.52 & NS \\
\hline $\operatorname{MCHC}(\mathrm{g} / \mathrm{dl})$ & 35.9 & $2 \cdot 1$ & $36 \cdot 7$ & $2 \cdot 1$ & 1.06 & NS \\
\hline $\operatorname{RBC}\left(+10^{12} / 1\right)$ & $4 \cdot 32$ & 0.35 & $4 \cdot 13$ & 0.50 & -1.22 & NS \\
\hline $\operatorname{MCV}(f)$ & $74 \cdot 1$ & $7 \cdot 7$ & $77 \cdot 6$ & $6 \cdot 1$ & 1.41 & NS \\
\hline Platelets $\left(\times 10^{9} / 1\right)$ & 343 & 107 & 274 & 82 & $-2 \cdot 02$ & NS \\
\hline $\log (\%$ retics +1$)$ & $1 \cdot 37(2 \cdot 9)$ & 0.47 & $1 \cdot 74(4 \cdot 7)$ & 0.45 & $2 \cdot 24$ & $\mathrm{p}<0.05$ \\
\hline Serum Fe $(\mu \mathrm{g} / \mathrm{dl})$ & $74 \cdot 0$ & $20 \cdot 0$ & $74 \cdot 4$ & $44 \cdot 0$ & 0.03 & NS \\
\hline $\mathrm{n}$ & 15 & & 16 & & & \\
\hline
\end{tabular}

NS $=$ not significant $(p>0.05)$.

Figures in parentheses represent means re-expressed in original units.

better fit than $\mathrm{HbF}$ levels. The best fitting model was found to include terms for sex, reticulocytes, and ISC counts. The effect of total haemoglobin noted in analysis of variance was no longer apparent after allowing for the effect of $\mathrm{HbF}$.

The predominance of the male sex among patients with occlusion was unexplained by haematological indices, for although males had slightly lower levels of $\mathrm{HbF}$ than females the difference was not sufficient to account for the observed sex difference in vasoocclusion.

Clinical events. The number of children affected by various clinical events failed to show any significant differences between the 3 retinal closure groups (Table 3). The mean number of events per child was not a useful measure for many symptoms, since it was unduly influenced by patients with extreme values. For example, there were more episodes of painful crisis and infarction in group I (80) than in groups II (64) and III (55), because one SS patient in group I had 27 episodes.

Height and weight were significantly less in group II than in group III $(\mathrm{p}<0.05)$, but the absence of any overall difference between groups I, and groups II and III combined, indicated that this was probably a chance effect without clinical significance.

Table 5 Comparison of clinical events in SC patients according to degree of peripheral retinal closure

\begin{tabular}{lcccl}
\hline & $I$ & $I I$ & $\chi^{2}$ & Significance $^{*}$ \\
\hline Dactylitis & 2 & 1 & $0 \cdot 74$ & NS \\
Pneumonia & 5 & 6 & $0 \cdot 05$ & NS \\
Crisis and infarction & 7 & 11 & $0 \cdot 99$ & NS \\
Gastroenteritis & 6 & 12 & $2 \cdot 97$ & NS \\
Weight loss $5 \%$ & 5 & 5 & $0 \cdot 10$ & NS \\
Temperature $102^{\circ} \mathrm{F}$ & 6 & 9 & $0 \cdot 59$ & NS \\
\hline
\end{tabular}

${ }^{*}$ Mantel-Haenzsel $\chi^{2}$ allowing for age group. NS=not significant $(p>0 \cdot 05)$. A $\chi^{2}$ value of 3.84 would be required for significance of the $5 \%$ level.
SC DISEASE

Age and sex distribution. Age and sex distribution in the 2 major groups as shown in Table 1 failed to reveal any differences.

Haematological indices. Comparison of haematological indices in patients with and without closure (Table 4) failed to reveal differences in mean total haemoglobin or mean $\mathrm{HbF}$ levels, but reticulocytes were significantly higher in the group with closure. A reduction in mean platelet count in this group just failed to reach significance at the 5\% level.

Clinical events. Comparison of clinical events (Table 5) indicated no significant differences between the groups. A history of gastroenteritis occurred twice as commonly in the group with closure, but this difference was not significant. The mean number of episodes of gastroenteritis $(1.4$ in the closure group, $1 \cdot 1$ in those without closure) also failed to reach significance.

Height $(\mathrm{p}<0.05)$ and weight $(\mathrm{p}<0.01)$ were significantly less in patients with vaso-occlusion than in those without.

\section{Discussion}

The tendency to small-vessel obstruction characteristic of sickle cell disease may be observed directly in the retinal vasculature. Areas of retinal nonerfusion occurred frequently in children before the age of 9 years and were seen more frequently in those with SS disease than in the generally milder SC disease.

The mechanism of such nonperfusion is presumed to be vessel obstruction by sickled cells, and the significant relationships with low fetal haemoglobin or high ISC counts are compatible with this. The grade of vessel primarily affected is unknown, physiological considerations implicating the capillary or venous level, although Galinos and colleagues? favoured a primary arteriolar obstruction. It is difficult to extrapolate from studies on other capillary 
beds, since the retinal circulation is clearly highly specialised and anatomically unusual, with relatively high oxygen extraction by the retina and oxygen diffusion occurring from both the vitreous and the choroid. Although controversy may surround the level of vessel primarily involved, the process of remodelling the peripheral vasculature has been excellently reviewed. ${ }^{7}$ It has been suggested that temporary recurrent arterial obstruction leads to progressive attrition of retinal capillaries and finally retinal nonperfusion. Factors affecting this process include the ability of the capillary bed to withstand periods of stasis, the potential to form bypass channels, and the tendency to develop and maintain new vessels.

Variations in the latter process may contribute to the difference in observed prevalence of proliferative retinopathy (PSR) in SS and SC disease. Although PSR has not yet been observed in children in the cohort study, it is logical to presume after the results of other studies ${ }^{89}$ that it will be more common in SC disease. If there is a simple relationship between retinal vaso-occlusion and the development of PSR, the observation that vaso-occlusion occurs more frequently in SS disease implies that some factor inhibits the progress to PSR in this genotype. Such a factor could be autoinfarction. It is recognised that further vaso-occlusion of new vessels producing autoinfarction is more common in SS disease ${ }^{10}$ and the high prevalence of PSR in SC disease may simply reflect a lesser tendency to autoinfarction.

Previous haematological analyses indicated PSR in SS disease to be significantly related to high total haemoglobin levels, and the apparent relationship between vaso-occlusion and low haemoglobin levels in the present study was unexpected. However, since low haemoglobin levels are associated with low fetal haemoglobin levels (Hayes and Serjeant, unpublished observations), it is likely that the apparent relationship with low total haemoglobin levels was entirely secondary to low $\mathrm{HbF}$ levels, and this was confirmed by logistic regression analysis.

In view of the relationship between vaso-occlusion and haematological indices the lack of correlation with clinical features was unexpected, especially since several of these are known to be related to low $\mathrm{HbF}$ or high ISC counts.
Events giving rise to dehydration and haemoconcentration might have been expected to be associated with a greater prevalence of vaso-occlusion in sickle cell disease. Special attention was therefore paid to illnesses with weight loss greater than or equal to $5 \%$ body weight or pyrexia greater than or equal to $102^{\circ} \mathrm{F}$ $\left(38.9^{\circ} \mathrm{C}\right)$, but no differences were apparent between patients with and without occlusion. A history of gastroenteritis was twice as common in SC patients with closure as in those without, but this and the mean number of episodes of gastroenteritis per patient failed to reach statistical significance, and there was no suggestion of difference in SS patients with and without closure. The speculation that episodes of dehydration might have been aetiologically important in retinal vaso-occlusion was therefore not supported by the data in these patients.

The only significant clinical association was between vaso-occlusion and low weight and height in children with SC disease, a surprising observation, since an abnormal body build is not characteristic of SC disease.

\section{References}

1 Hayes RJ, Condon PI, Serjeant GR. Haematological factors associated with proliferative retinopathy in homozygous sickle cell disease. Br J Ophthalmol 1981; 65: 29-35.

2 Hayes RJ, Condon PI, Serjeant GR. Haematological factors associated with proliferative retinopathy in sickle cell haemoglobin C disease. Br J Ophthalmol 1981; 65: 712-7.

3 Talbot JF, Bird AC, Serjeant GR, Hayes RJ. Sickle cell retinopathy in young children in Jamaica. Br J Ophthalmol 1982; 66: 149-54.

4 Serjeant GR, Grandison Y, Lowrie Y, et al. The development of haematological changes in homozygous sickle cell disease: a cohort study from birth to 6 years. Br J Haematol 1981; 48: 553-43.

5 Serjeant GR, Serjeant BE, Milner PF. The irreversibly sickled cell: a determinant of haemolysis in sickle cell anaemia. $\mathrm{Br} \mathrm{J}$ Haematol 1969; 17: 527-33.

6 Nelder JA, Wedderburn RWN. Generalised linear models. JR Statist Soc (A) 1972; 135: 370-84.

7 Galinos SO, Asdourian GK, Woolf MB, et al. Spontaneous remodelling of the peripheral retinal vasculature in sickling disorders. Am J Ophthalmol 1975; 79: 853-70.

8 Condon PI, Serjeant GR. Ocular findings in homozygous sickle cell anemia in Jamaica. Am J Ophthalmol 1972; 73: 533-43.

9 Condon PI, Serjeant GR. Ocular findings in hemoglobin SC disease in Jamaica. Am J Ophthalmol 1972; 74: 921-31.

10 Condon PI, Serjeant GR. Behaviour of untreated proliferative sickle retinopathy. Br J Ophthalmol 1980; 64: 404-11. 